\title{
ETNOBOTANI TUMBUHAN RITUAL YANG DIGUNAKAN PADA UPACARA JAMASAN DI KERATON YOGYAKARTA
}

\section{ETNOBOTANY RITUAL PLANTS THAT USED ON JAMASAN CEREMONY IN YOGYAKARTA PALACE}

\author{
Lily Yulia Surya Sari ${ }^{1}$, Farah Diba Setiana $\mathrm{W}^{2}$, Rina Setyawati ${ }^{3}$ \\ ${ }^{1}$ AKAFARMA 17 Agustus Semarang, ${ }^{2,3}$.STIKes Kesetiakawanan Sosial Indonesia \\ e-mail : dibafarah27@gmail.com
}

\begin{abstract}
Abstrak
Indonesia memiliki lebih dari 350 etnis, setiap etnis mempunyai budaya, termasuk diantaranya upacara adat/ritual, salah satu ritual yang dilakukan oleh Keraton Yogyakarta adalah Upacara Jamasan Pusaka. Pada upacara jamasan ini biasanya banyak digunakan berbagai jenis sesaji yang berasal dari tumbuhan utuh atau bagian tumbuhan yang diolah menjadi makanan, minuman, dan hiasan. Penelitian ini dilaksanakan pada bulan November 2014. Data pada penelitian ini meliputi makna filosofis tumbuhan yang digunakan pada upacara jamasan, dan jenis tumbuhan yang digunakan pada upacara jamasan. Data pada penelitian ini diperoleh dengan cara deep Interview dengan informan kunci abdi dalem Keraton. Data pada penelitian ini dianalisa secara deskriptif kuantitatif dan deskriptif kualitatif. Hasil pada penelitian ini adalah tumbuhan yang paling banyak digunakan dalam upacara jamasan pusaka berasal dari famili Zingiberaceae dan Poaceae sebanyak $7,44 \%$. Urutan kedua tumbuhan yang paling banyak digunakan pada upacara jamasan pusaka adalah famili Papilionaceae dan Myrtaceae 5,33\%. Bagian tumbuhan yang paling banyak digunakan pada upacara jamasan pusaka adalah buah sebesar $39,8 \%$ dan daun $15,9 \%$.
\end{abstract}

Kata Kunci : Etnobotani, Tumbuhan ritual, Jamasan, Keraton Yogyakarta.

\begin{abstract}
Indonesia has more than 350 ethnicities, each ethnic group has a culture, including traditional ceremonies / rituals, one of the rituals carried out by the Yogyakarta Palace is the Jamasan Pusaka Ceremony. At the Jamasan ceremony, many types of offerings are usually used from whole plants or parts of plants that are processed into food, drinks, and decorations. This research was conducted in November 2014. The data in this study included the philosophical meanings of plants used at the Jamasan ceremony, and the types of plants used at the Jamasan ceremony. The data in this study were obtained by means of deep interviews with key informants of the courtiers in the palace. The data in this study were analyzed in quantitative descriptive and qualitative descriptive. The results of this study were the most widely used plants in the heirloom ceremony originating from the family Zingiberaceae and Poaceae as much as 7.44\%. The second most used sequence of plants in the heirloom ceremony is the Papilionaceae and Myrtaceae families $5.33 \%$. The most used part of the plant in the heirloom ceremony is fruit of $39.8 \%$ and leaves of $15.9 \%$.
\end{abstract}

Keywords: Ethnobotany, ritual plants, Jamasan, Keraton Yogyakarta. 


\section{Pendahuluan}

Indonesia memiliki lebih dari 350 etnis, setiap etnis mempunyai budaya, termasuk diantaranya upacara adat/ritual. Sebagian besar tradisi upacara ritual di Indonesia menggunakan tumbuhan-tumbuhan tertentu. Anggana (2001) menyebutkan bahwa kepercayaan masyarakat adat merupakan suatu tradisi dan budaya yang tidak dapat dipisahkan dari tumbuhan. Hubungan tersebut menunjukkan eratnya hubungan antara masyarakat/etnis dengan tumbuhan dalam pemanfaatannya dalam kegiatan ritual (Kartiwa dan Wahyono, 1992). Hubungan antara manusia dan tumbuhan dipelajari pada suatu disiplin ilmu yang disebut etnobotani. Kegiatan upacara ritual di Keraton Yogyakarta masih terjaga dari waktu ke waktu. Upacara ritual yang diteliti adalah upacara ritual yang bersifat komunal, atau perayaan yang besar. Kegiatan ritual ini dapat dikatakan sering dan berkelanjutan dilakukan oleh pihak keraton, upacara ritual yang selalu dilakukan tiap tahun di antaranya adalah upacara jamasan pusaka.

Jamasan dapat diartikan siraman yaitu memandikan secara keseluruhan. Nyirami atau njamasi adalah memandikan atau membersihkan bilah keris, tombak atau tosan aji lain dari kotoran, debu, jamur dan sisa minyak pusaka yang sudah tengik. (Harsrinuksmo, 2004). Pada upacara jamasan ini biasanya banyak digunakan berbagai jenis sesaji yang terdiri dari makanan, minuman, buah - buahan, dan bunga.

Penggunaan tumbuhan dalam upacara ritual ini menuntut ketersediaan berbagai jenis tumbuhan yang digunakan dalam upacara ritual khusunya upacara jamasan pusaka. Ketersediaan berbagai jenis tumbuhan yang digunakan pada upacara ritual khususnya upacara jamasan pusaka menuntut adanya konservasi pada beberapa jenis tumbuhan.

\section{Metode Penelitian}

Objek pada penelitian ini adalah jenis tumbuhan yang digunakan untuk ritual jamasan pusaka. Penelitian ini dilakukan pada November 2014 di Keraton Yogyakarta. Data Pada Penelitian ini diambil dengan cara deep interview dengan informan kunci sesepuh dan abdi dalem Keraton Yogyakarta dan Observasi Partisipatif Upacara Jamasan. Data pada penelitian ini meliputi makna filosofis tumbuhan yang digunakan dalam ritual upacara jamasan, dan data jenis tumbuhan, bagian tumbuhan, dan jumlah yang digunakan yang digunakan dalam upacra jamasan. Data mengenai jenis tumbuhan yang digunakan pada upacara jamasan dianalisa secara deskriptif kualitatif sedangkan bagian tumbuhan yang digunakan sebagai sesaji upacara ritual dianalisa dengan cara deskriptif kuantitatif dengan rumus persentase sebagai berikut,

\section{Persentase organ tumbuhan $=$ $\frac{\Sigma \text { organ tumbuhan tertentu }}{\Sigma \text { seluruh organ tumbuhan }} \times 100 \%$}




\section{Hasil dan Pembahasan}

\section{Hasil Penelitian}

Keanekaragaman tumbuhan yang digunakan dalam upacara ritual jamasan tergambar pada tabel 1 berikut ini,

Tabel 1. Keanekaragaman Jenis Tumbuhan Ritual yang Digunakan Pada Upacara Jamasan di Keraton Yogyakarta.

\begin{tabular}{|c|c|c|c|}
\hline No & Nama Tumbuhan & Nama Lokal & Famili \\
\hline 1 & Aleurites moluccana (L.) Wild. & Kemiri & Euphorbiaceae \\
\hline 2 & Allium cepa L. & Bawang merah & Amaryllidaceae \\
\hline 3 & Allium fistulosum & Bawang daun & Alliaceae \\
\hline 4 & Allium sativum $\mathrm{L}$. & Bawang putih & Alliaceae \\
\hline 5 & Alpinia galanga & Lengkuas & Zingiberaceae \\
\hline 6 & Amaranthus tricolor $\mathrm{L}$. & Bayam & Amaranthaceae \\
\hline 7 & Amomum cardamomum auct. & Kapulaga & Zingiberaceae \\
\hline 8 & Amorphopalus companulatus Dence. & Suweg & Araceae \\
\hline 9 & Ananas comosus (L.) Merr. & Nanas & Bromeliaceae \\
\hline 10 & Annona squamosa L. & Srikaya & Annonaceae \\
\hline 11 & Apium graviolens $\mathrm{L}$. & Seledri & Apiaceae \\
\hline 12 & Arachis hypogaea $\mathrm{L}$. & Kacang tanah & Papilionaceae \\
\hline 13 & Arenga pinnata (Wurmb) Merr. & Aren & Arecaceae \\
\hline 14 & Artocarpus camansi (Parkinson) Fosberg & Kluwih & Moraceae \\
\hline 15 & Artocarpus heterophyllus Lamk. & Nangka & Moraceae \\
\hline 16 & Averrhoa bilimbi & Belimbing wuluh & Oxilidaceae \\
\hline 17 & Averrhoa carambola & Belimbing lingir & Oxilidaceae \\
\hline 18 & Bambusa glaucescens & Bambu & Poaceae \\
\hline 19 & Beosenbergia rotunda (L.) Mansf. & Temu kunci & Zingiberaceae \\
\hline 20 & Borassus flabellifer & Siwalan/Lontar & Arecaceae \\
\hline 21 & Brassica oleraceae L. & Kubis & Brassicaceae \\
\hline 22 & Canangiun odorata (Lam.) & Kenanga & Annonaceae \\
\hline 23 & Capsicum annuum & Cabai merah & Solanaceae \\
\hline 24 & Capsicum frutescens & Cabai rawit & Solanaceae \\
\hline 25 & Carica papaya L. & Pepaya & Caricaceae \\
\hline 26 & Cinnamomum burmanni & Kayu manis/ & Lauraceae \\
\hline 27 & Citrulus lanatus (Thunb.) Matsum. \& Nakai & Semangka & Cucurbitaceae \\
\hline 28 & Citrus aurantifolia (Christm.) Swingle. & Jeruk nipis & Rutaceae \\
\hline 29 & Citrus nobilis Lour. & Jeruk keprok & Rutaceae \\
\hline 30 & Citrus hystrix DC. & Jeruk purut & Rutaceae \\
\hline 31 & Cocos nucifera $\mathrm{L}$ & Kelapa & Arecaceae \\
\hline 32 & Coffea Arabica & Kopi & Rubiaceae \\
\hline 33 & Coleus tuberosus Benth & Kentang hitam & Lamiaceae \\
\hline 34 & Colocasia esculenta (L.) Schott & Talas & Araceae \\
\hline 35 & Coriandrum sativum L. & Ketumbar & Apiaceae \\
\hline 36 & Cucumis melo L. & Melon & Cucurbitaceae \\
\hline 37 & Cucumis sativus $\mathrm{L}$. & Mentimun & Cucurbitaceae \\
\hline 38 & Cucurbita pepo & Labu kuning/Waluh & Cucurbitaceae \\
\hline 39 & Curcuma domestica Val. & Kunyit & Zingiberaceae \\
\hline 40 & Daucus carota L. & Wortel & Apiaceae \\
\hline 41 & Dioscorea esculenta L. & Gembili & Dioscoreaceae \\
\hline 42 & Dioscorea hispida Dennst. & Gadung & Dioscoreaceae \\
\hline 43 & Erythrina lithosperma & Dadap serep & Papilionaceae \\
\hline 44 & Eugena cumini (L.) Druce & Jamblang/Duwet & Myrtaceae \\
\hline 45 & Eugenia aperculata & Salam & Myrtaceae \\
\hline 46 & Eugenia aquea & Jambu air & Myrtaceae \\
\hline 47 & Eugenia aromaticum & Cengkeh & Myrtaceae \\
\hline 48 & Ficus benjamina & Beringin & Moraceae \\
\hline 49 & Garcinia mangostana L. & Manggis & Clusiaceae \\
\hline 50 & Gnetum gnemon & Melinjo & Gnetaceae \\
\hline 51 & Gossypium hirsutum L. & Kapas & Malvaceae \\
\hline 52 & Imperata cylindrica L. & Alang-alang & Poaceae \\
\hline 53 & Ipomoea aquatica Forssk. & Kangkung & Convolvulaceae \\
\hline 54 & Ipomoea batatas $\mathrm{L}$. & Ubi jalar & Convolvulaceae \\
\hline $\mathrm{DE}$ & HAS & & VE) 101 \\
\hline
\end{tabular}




\section{BIOMA : JURNAL BIOLOGI MAKASSAR, 4(2): 99-106, JULI-DES 2019}

\begin{tabular}{|c|c|c|c|}
\hline 55 & Jasminum sp. & Melati & Oleaceae \\
\hline 56 & Juniperus sp. & Juniper & Cupressaceae \\
\hline 57 & Kaempferia galanga (Linn.) & Kencur & Zingiberaceae \\
\hline 58 & Lansium domesticum & Duku & Meliaceae \\
\hline 59 & Malus silveltris. & Apel merah & Rosaceae \\
\hline 60 & Mangifera indica & Mangga & Anacardiaceae \\
\hline 61 & Manihot esculenta Crantz. & Singkong & Euphorbiaceae \\
\hline 62 & Manilkara zapota (L.) P. Royen & Sawo manila & Sapotaceae \\
\hline 63 & Michelia champaca & Cempaka/Kantil & Magnoliaceae \\
\hline 64 & Morinda citrifolia & Pace/Mengkudu & Rubiaceae \\
\hline 65 & Musa acuminate $\mathrm{L}$. & Pisang kapok & Musaceae \\
\hline 66 & Musa paradisiaca L. & Pisang & Musaceae \\
\hline 67 & Myristica fragrans & Pala & Myristicaceae \\
\hline 68 & Nephelium lappaceum L. & Rambutan & Sapindaceae \\
\hline 69 & Nicotiana tabacum L. & Tembakau & Solanaceae \\
\hline 70 & Ocimum basilicum var anisatum & Kemangi & Lamiaceae \\
\hline 71 & Oryza sativa var. glutinosa & Ketan & Poaceae \\
\hline 72 & Oryza sativa $\mathrm{L}$. & Padi & Poaceae \\
\hline 73 & $\begin{array}{c}\text { Pachirrhizus erosus (L.) Urb. } \\
\text { Pandanus }\end{array}$ & Bengkuang & Papilionaceae \\
\hline 74 & amaryllfolium Roxb. & Pandan wangi & Pandanaceae \\
\hline 75 & Papaver somniferum $\mathrm{L}$. & Candu/Opium & Papaveraceae \\
\hline 76 & Phaseolus radiatus & Kacang hijau & Papilionaceae \\
\hline 77 & Phaseolus vulgaris & Kacang panjang & Papilionaceae \\
\hline 78 & Piper betle & Sirih & Piperaceae \\
\hline 79 & Piper nigrum L. & Lada/Merica & Piperaceae \\
\hline 80 & Pisum sativum $\mathrm{L}$. & Kapri & Fabaceae \\
\hline 81 & Psidium guajava & Jambu biji & Myrtaceae \\
\hline 82 & Pyrus malus L. & Apel malang & Rosaceae \\
\hline 83 & Rossa sp. & Mawar & Rosaceae \\
\hline 84 & Saccharum officinarum $\mathrm{L}$. & Tebu & Poaceae \\
\hline 85 & Salacca zalacca (Gaertn.) Voss & Salak & Arecaceae \\
\hline 86 & Santalum album L. & Cendana & Santalaceae \\
\hline 87 & Soya max Piper. & Kedelai & Papilionaceae \\
\hline 88 & Stelecocarpus burahol (Blume) Hook. \& Thomson & Kepel & Annonaceae \\
\hline 89 & Styrax officinalis & Kemenyan & Styracaceae \\
\hline 90 & Tamarindus indica $\mathrm{L}$. & Asam jawa & Fabaceae \\
\hline 91 & Triticum aestivum $\mathrm{L}$. & Gandum & Poaceae \\
\hline 92 & Uncaria gambir (Hunt.) Roxb. & Gambir & Rubiaceae \\
\hline 93 & Vigna unguiculata & $\begin{array}{l}\text { Kacang tholo/ } \\
\text { tunggak/dadap }\end{array}$ & Fabaceae \\
\hline 94 & Vitis vinivera $\mathrm{L}$. & Anggur & Vitaceae \\
\hline 95 & Zea mays L. & Jagung & Poaceae \\
\hline 96 & Zingiber casumounar & Bangle/Bengle & Zingiberaceae \\
\hline 97 & Zingiber officinale & Jahe & Zingiberaceae \\
\hline
\end{tabular}

${ }^{*}$ Data Primer

Bagian tumbuhan dan jumlah yang digunakan pada upacara jamasan tersaji pada tabel 2 berikut ini,

Tabel 2. Bagian Tumbuhan dan Jumlah Tumbuhan yang digunakan pada Upacara Jamasan.

\begin{tabular}{cccc}
\hline No & Nama Tumbuhan & Bagian & Jumlah \\
1 & biji & 7 \\
2 & Aleurites moluccana (L.) Wild. & umbi & 4 \\
3 & Allium cepa L. & daun, batang & 3 \\
4 & Allium fistulosum & umbi & 5 \\
\hline 5 & Allium sativum L. & rimpang & daun \\
6 & Alpinia galanga & buah, biji & 4 \\
7 & Amaranthus tricolor L. & umbi & 2 \\
8 & Amomum cardamomum auct. & batang & 3 \\
9 & Amorphopalus companulatus Dence. & buah & 4 \\
10 & Ananas comosus (L.) Merr. & daun & 4 \\
12 & Annona squamosa L. & buah, biji
\end{tabular}




\begin{tabular}{|c|c|c|c|}
\hline 13 & Arenga pinnata (Wurmb) Merr. & batang & 5 \\
\hline 14 & Artocarpus camansi (Parkinson) Fosberg & buah & 3 \\
\hline 15 & Artocarpus heterophyllus Lamk. & buah & 4 \\
\hline 16 & Averrhoa bilimbi & buah & 2 \\
\hline 17 & Averrhoa carambola & buah & 4 \\
\hline 18 & Bambusa glaucescens & batang & 7 \\
\hline 19 & Beosenbergia rotunda (L.) Mansf. & rimpang & 4 \\
\hline 20 & Borassus flabellifer & batang & 3 \\
\hline 21 & Brassica oleraceae L. & bunga & 5 \\
\hline 22 & Canangiun odorata (Lam.) Hook.f. \& Thomson & buah & 6 \\
\hline 23 & Capsicum annuum & buah & 5 \\
\hline 24 & Capsicum frutescens & buah & 4 \\
\hline 25 & Carica papaya $\mathrm{L}$. & buah & 4 \\
\hline 26 & Cinnamomum burmanni & kulit & 4 \\
\hline 27 & Citrulus lanatus (Thunb.) Matsum. \& Nakai & buah & 3 \\
\hline 28 & Citrus aurantifolia (Christm.) Swingle. & buah & 3 \\
\hline 29 & Citrus nobilis Lour. & buah & 6 \\
\hline 30 & Citrus hystrix DC. & buah & 3 \\
\hline 31 & Cocos nucifera L. & daun, buah, biji & 5 \\
\hline 32 & Coffea Arabica & biji & 3 \\
\hline 33 & Coleus tuberosus Benth & umbi & 3 \\
\hline 34 & Colocasia esculenta (L.) Schott & umbi & 3 \\
\hline 35 & Coriandrum sativum L. & buah, biji & 4 \\
\hline 36 & Cucumis melo L. & buah & 3 \\
\hline 37 & Cucumis sativus L. & buah & 5 \\
\hline 38 & Cucurbita pepo & buah & 3 \\
\hline 39 & Curcuma domestica Val. & rimpang & 5 \\
\hline 40 & Daucus carota L. & umbi & 4 \\
\hline 41 & Dioscorea esculenta L. & umbi & 3 \\
\hline 42 & Dioscorea hispida Dennst. & umbi & 3 \\
\hline 43 & Erythrina lithosperma & daun & 1 \\
\hline 44 & Eugena cumini (L.) Druce & buah & 4 \\
\hline 45 & Eugenia aperculata & daun & 5 \\
\hline 46 & Eugenia aquea & buah & 5 \\
\hline 47 & Eugenia aromaticum & buah & 4 \\
\hline 48 & Ficus benjamina & daun & 1 \\
\hline 49 & Garcinia mangostana L. & buah & 4 \\
\hline 50 & Gnetum gnemon & daun, biji & 4 \\
\hline 51 & Gossypium hirsutum & biji & 2 \\
\hline 52 & Imperata cylindrica L. & daun & 1 \\
\hline 53 & Ipomoea aquatica Forssk. & daun, batang & 4 \\
\hline 54 & Ipomoea batatas L. & umbi & 5 \\
\hline 55 & Jasminum sp. & bunga & 7 \\
\hline 56 & Juniperus sp. & buah & 3 \\
\hline 57 & Kaempferia galanga (Linn.) & rimpang & 5 \\
\hline 58 & Lansium domesticum & buah & 4 \\
\hline 59 & Malus silveltris & buah & 4 \\
\hline 60 & Mangifera indica & buah & 3 \\
\hline 61 & Manihot esculenta Crantz. & daun, umbi & 4 \\
\hline 62 & Manilkara zapota (L.) P. Royen & buah & 6 \\
\hline 63 & Michelia champaca & bunga & 7 \\
\hline 64 & Morinda citrifolia & daun & 1 \\
\hline 65 & Musa acuminate L. & daun, batang, buah & 4 \\
\hline 66 & Musa paradisiaca L. & daun, batang, buah & 6 \\
\hline 67 & Myristica fragrans & biji & 2 \\
\hline 68 & Nephelium lappaceum L. & buah & 5 \\
\hline 69 & Nicotiana tabacum L. & daun & 4 \\
\hline 70 & Ocimum basilicum var anisatum & daun & 5 \\
\hline 71 & Oryza sativa var. glutinosa & buah, biji & 5 \\
\hline 72 & Oryza sativa L. & batang, buah, biji & 6 \\
\hline 73 & Pachirrhizus erosus (L.) Urb. & umbi & 5 \\
\hline 74 & Pandanus amaryllfolium Roxb. & daun & 4 \\
\hline 75 & Papaver somniferum L. & buah & 3 \\
\hline 76 & Phaseolus radiatus & biji & 4 \\
\hline 77 & Phaseolus vulgaris & buah & 5 \\
\hline 78 & Piper betle & daun & 5 \\
\hline 79 & Piper nigrum L. & buah, biji & 4 \\
\hline 80 & Pisum sativum $\mathrm{L}$. & buah & 4 \\
\hline
\end{tabular}




\section{BIOMA : JURNAL BIOLOGI MAKASSAR, 4(2): 99-106, JULI-DES 2019}

\begin{tabular}{ccc} 
& & \\
81 & Psidium guajava & buah \\
82 & Pyrus malus L. & buah \\
83 & Rossa sp. & bunga \\
84 & Saccharum officinarum L. & 5 \\
85 & Salacca zalacca (Gaertn.) Voss & 7 \\
86 & Santalum album L. & buah \\
87 & Soya max Piper. & batang \\
88 & Stelecocarpus burahol (Blume) Hook. \& & 6 \\
89 & Thomson & buah \\
90 & Styrax officinalis & batang \\
91 & Tamarindus indica L. & buah \\
92 & Triticum aestivum L. & biji \\
93 & Uncaria gambir (Hunt.) Roxb. & daun, batang \\
94 & Vigna unguiculata & biji \\
95 & Vitis vinivera L. & buah \\
96 & Zea mays L. & buah \\
97 & Zingiber casumounar & rimpang \\
& Zingiber officinale & rimpang \\
\hline
\end{tabular}

${ }^{*}$ Data Primer

Berdasarkan tabel 1 diketahui jika tumbuhan yang paling banyak digunakan dalam upacara jamasan pusaka berasal dari famili Zingiberaceae dan Poaceae sebanyak 7,44\%. Urutan kedua tumbuhan yang paling banyak digunakan pada upacara jamasan pusaka adalah famili Papilionaceae dan Myrtaceae 5,33\%.

Berdasarkan tabel 2 dapat diketahui bahwa bagian tumbuhan yang paling banyak digunakan pada upacara jamasan pusaka adalah buah sebesar $39,8 \%$ dan daun $15,9 \%$.

\section{Pembahasan}

Upacara Jamasan Pusaka menggunakan berbagai macam sesaji yang dipersembahkan kepada berbagai macam benda pusaka yaitu berupa tombak (21 buah), keris ( 6 buah), pedang (1 buah), wedung (1 buah), bendera (4 buah), alat angkut ( 1 buah), alat masak berupa periuk (1 buah), bendhe (4 buah), kendang ( 1 buah), gamelan ( 4 buah), kitab (3 buah), kereta (10 buah) benda pusaka dari emas (10 buah), dan lain - lain (Suyami, 2008).

Zingiberaceae dan Poaceae. Zingiberaceae menjadi tanaman yang paling banyak digunakan. Bagian tumbuhan yang banyak digunakan pada upacara jamasan adalah buah sebanyak $39,8 \%$ buah - buahan ini digunakan sebagai bahan pembuat sesaji pada upacara jamasan. Pada upacara jamasan pusaka disebabkan karena sebelum upacara jamasan pusaka dilakukan terlebih dahulu dilakukan sugengan (selamatan) dengan menyajikan berbagai jenis makanan pokok seperti jagung, tebu, gandum yang tergolong family Poaceae. Makanan yang digunakan sebagai sugengan dimasak menggunakan bumbu dapur yang tergolong Zingiberaceae seperti jahe, kencur, kunyit. Hal ini sesuai dengan pendapat Suyono (1985) yang menyatakan dalam upacara jamasan pusaka tersebut menggunakan beberapa sesaji karena dipercaya sesaji akan memperlancar jalannya prosesi jamasan pusaka. Sesaji yang disiapkan berupa makanan kecil, bendabenda kecil, bunga-bungaan serta hiasan.

Berdasarkan Wawancara dengan KRT Puntadewa diketahui bahwa Sesaji Jamasan Pusaka meliputi menyan 'kemenyan’, jadah `jadah', krupuk ‘krupuk’, ingkung 'ingkung', rengginang 'ceriping/rengginang', tumpeng 'tumpeng', panggang 'panggang', peyek 'rempeyek', kolak 'kolak', serundeng 'serundeng', mihun 'mie bihun', dhuwit 'uang', gudhangan 'gudangan', lalaban 'lalaban', jenang baro-baro 'bubur baro-baro', panjang ilang 'panjang ilang', gedhang raja 'pisang raja', kembang setaman 'bunga setaman`, pala kependhem 'biji atau buah yang terpendam dalam tanah', jenang sengkala 'bubur sengkala', jajan pasar 'jajan pasar', tempe kering 'kering tempe', sega asahan

DEPARTEMEN BIOLOGI FMIPA UNHAS |2528-7168 (PRINT); 2548-6659 (ON LINE) 104 
'nasi asahan', sega golong 'nasi golong', pencok bakal 'pencok bakal', sambel goreng 'sambal goreng', sega putih 'nasi putih', sega gurih 'nasi gurih', jenang abang putih 'bubur merah putih', dhele ireng 'kedelai hitam', tahu tempe bacem 'bacem tempe tahu', dan kinang komplit `kinang lengkap`

Berdasarkan wawancara dengan KRT Puntadewa dan Kanjeng Sepuh Widya Winata diketahui bahwa kelengkapan sesaji tersebut memiliki makna filosofi, makna filosofi dari berbagai sesaji tersebut di antaranya, kemenyan (menyan) digunakan sebagai persembahan kepada tuhan, asap dupa yang membumbung lurus tidak bergerak ke kanan dan kiri merupaka perlambang sesajinya diterima. Jadah mempunyai makna hajate 'keperluan` sudah terpenuhi. Maksudnya persyaratan-persyaratan upacara jamasan sudah dapat terpenuhi sehingga diharapkan dapat berjalan dengan baik tanpa suatu halangan apapun. Krupuk melambangkan dalam menjalani kehidupan jangan mudah patah/putus asa (krupuk jangan mlempem 'lembek’ harus renyah). Ingkung memiliki makna sebagai suatu pengorbanan secara tulus yang diperuntukkan kepada Tuhan maupun para leluhur yang telah memberikan keselamatan. Renginang memiliki makna kehidupan manusia mempunyai permohonan tidak hanya satu melainkan bermacam-macam. Tumpeng memiliki bentuk mengerucut ke atas semakin ke atas semakin lancip sebagai simbol keyakinan dan keteguhan iman kepada Allah.

Panggang adalah sebagai rasa syukur kepada Tuhan karena telah memberi perlindungan dan kemakmuran bagi masyarakat. Peyek sebagai lambang bersatunya kebudayaan dan masyarakat dalam mencapai tujuan bersama, dalam hal ini supaya terlaksana dengan baik prosesi jamasan. Kolak memiliki makna sebagai tolak bala 'menolak bahaya' segala perbuatan jelek agar prosesi jamasan berjalan dengan baik. Srundeng merupakan simbol gandheng renteng maksudnya rentengrenteng urip 'kesejajaran dalam hidup' artinya antara lahir dan batin harus sejajar/seimbang. Dhuwit dhuwit sebagai sarana pengganti, diharapkan jika sesaji ada yang kurang uang tersebut dapat menggantikan. Gudangan 'gudangan melambangkan kesegaran sayuran melambangkan kesegaran jasmani dan rohani.

Lalaban makna lalaban yaitu diharapkan semua sesaji dapat sesuai tidak ada kekurangan. Atau dengan kata lain lalaban sebagai pelengkap sesaji yang lain. Jenang baro - baro makna lain jenang baro-baro yaitu bahwa kehidupan manusia tidak suci lagi, segala perbuatan cenderung berlaku menurut kehendaknya sendiri manusia sudah tidak ada yang ditakuti lagi. Gedhang Raja memiliki makna sebagai simbol agar pemimpin (raja) didukung oleh seluruh rakyatnya. Jenang sengkala memiliki makna sebagai penolak bala menolak mara bahaya yang dimungkinkan akan datang dan merusak jalannya prosesi, Jajan pasar sebagai simbol anggota masyarakat yang terdiri dari berbagai macam latar belakang sosial. Tempe kering mempunyai makna dalam perputaran kehidupan terkadang kita merasakan suka dan duka. Sega asahan sebagai lambang dari semua harapan yang telah selesai (sah) atau telah terlaksana tidak ada hal-hal yang kurang dan diharapkan semua warga masyarakat selalu mendapat berkah dari tuhan dengan kehidupan yang tentram. Sega golong melambangkan sebagai simbol agar supaya semua petugas jamasan mempunyai tekad yang bulat (golong) sehingga segala apa yang dicita-citakan akan dapat terlaksana dengan baik. Jenang abang putih merupakan bubur yang terbuat dari tepung terigu dan diberi warna gula jawa memiliki beberapa makna kultural.

Sega putih sebagai simbol keberuntungan dan penyajian nasi mengandung permohonan agar mendapat selamat dan mendapat rejeki. sega gurih sebagai simbol yang mengandung makna agar antara penjamas dan yang dijamasi terdapat ikatan seperti butirbutir nasi yang direkatkan dengan santan kelapa. Tahu tempe bacem yang terasa manis 
biasanya digunakan sebagai lawuhan pelengkap makanan. Kinang komplit bertujuan supaya manusia menghormat terhadap sumber kehidupan yaitu dunia seisinya ini.

Tumbuhan yang memiliki makna filosofi pada upacara jamasan pusaka diantaranya tumbuhan kelapa, bunga mawar, bunga melati, dan bunga kenanga..Bunga mawar memiliki makna proses terjadinya atau lahirnya diri kita ke dunia fana. Memiliki makna lambang dumadine jalma menungsa melalui langkah triwikrama. Bunga Melati memiliki makna bahwa setiap orang melakukan segala kebaikan hendaklah melibatkan hati (sembah kalbu), jangan hanya dilakukan secara gerak ragawi saja. Bunga Kenanga memiliki makna Kenang-En Ing Angga yaitu bermakna filosofis agar supaya anak turun selalu mengenang, semua "pusaka" warisan leluhur berupa bendabenda seni, tradisi, kesenian, kebudayaan, filsafat, dan ilmu spiritual yang banyak mengandung nilai-nilai kearifan lokal (local wisdom) (Affan, 2013). Bagian kelapa yang digunakan pada upacara jamasan adalah air kelapa yang memiliki makna mensucikan pusaka (Widiastutik, 2015).

\section{Kesimpulan}

Pada penelitian ini dapat disimpulkan bahwa upacara jamasan pusaka di Keraton Yogyakarta emnggunakan berbagai tumbuhan sebagai sesaji. Terdapat 97 jenis tumbuhan yang digunakan sebagai sesaji dengan persentase terbanyak tergolong famili zingiberaceae dan poaceae sebesar $7,44 \%$. Bagian tumbuhan yang banyak digunakan pada upacara jamasan adalah bagian buah sebesar $39,8 \%$. Tumbuhan yang digunakan pada upacara ini tidak hanya digunakan secara utuh, namun juga diolah untuk menjadi makanan atau minuman yang digunakan sebagai sesaji pada upacara jamasan.

\section{Daftar Pustaka}

Anggana, A.F. 2011. Kajian Etnobotani Di Sekitar Taman Nasional Gunung Merapi; Studi Kasus di Desa Umbulharjo, Sidorejo,Wonodoyo dan Ngablak. Skripsi ITB: tidak diterbitkan.

Ariyono, Suyono, 1985, Kamus Antropologi, Jakarta : Akademi Persindo.

Bambang,H. 2004. Ensiklopedi Keris, PT. Gramedia Pustaka Utama, Jakarta, 2004.

Kartiwa, S. dan Wahyono, M. 1992. Hubungan Antara Tumbuhan dan Manusia Dalam Upacara Adat di Indonesia. Dalam Prosiding Seminar Etnobotani dan Lokakarya Nasional Etnobotani. Bogor.

Muhammad Affan, 2013. Filsafat Kebudayaan, Yogyakarta: Pustaka Setia.

Suyami. 2008. Upacara Ritual di Keraton Yogyakarta: Refleksi Mithologi dalam Budaya Jawa. Yogyakarta: Kepel Press.

Widiastutik, F. D. 2015. Etnobotani Kelapa Sebagai Bahan Obat Tradisional Karaton Ngayogyakarta Hadiningrat. Tesis UNDIP: tidak diterbitkan. 